\title{
A BUSCA PELA FORMAÇÃO ESPECIALIZADA EM ENFERMAGEM DO TRABALHO POR ENFERMEIROSa
}

\author{
Potiguara de Oliveira PA Z ${ }^{\mathrm{b}}$, Dagmar Elaine KAISE R ${ }^{\mathrm{c}}$
}

\section{RESUM 0}

0 presente artigo problematiza e discute a busca pela formação especializada em Enfer magem do T rabal ho por enfermeiros. T rata-se de um estudo qualitativo exploratório descritivo cujos dados foram anal isados pela técnica de análise de conteúdo. A coleta dos dados deu-se em maio de 2010, com nove discentes de um curso de especialização que aceitar am participar do estudo, tendo todos os participantes assinado o Termo de Consentimento Livre e E sclarecido. Rege a busca da formação especial izada em E nfer magem do T rabal ho a per spectiva para uma atuação profissional em E nfer magem do T rabal ho e a especificidade dos conteúdos curriculares em saúde do trabal hador. Interfaces do processo educativo confirmam importantes contribuições para uma formação sólida, projetam o enfermeiro no patamar teórico/ acadêmico e compõe o itinerário para a for mação Stricto Sensu. Expectativas, motivações e potencialidades agregam contribuições para uma governança contextual izada do processo educativo e demandas da contemporaneidade para a E nfer magem do T rabal ho.

D escritores: Enfermagem do trabal ho. E ducação em enfermagem. E ducação superior. Saúde do trabal hador.

\section{RESUMEN}

E I artículo analiza y discutela búsqueda de la formación especializada en E nfermería del T rabajo por enfermeros. E studio cualitativo exploratorio descriptivo cuyos datos fueron analizados por la técnica del análisis de contenido. $L$ a recogida de datos ocurrió en mayo de 2010 con nueve estudiantes de un curso de especialización que aceptaron participar del estudio y todos los participantes firmaron el T érmino de Consentimiento L ibre eInformado. Rigela búsqueda de la formación especializada en E nfermería del T rabajo la perspectiva para una práctica profesional en E nfermería del T rabajo y la especificidad de los contenidos curriculares en salud del trabajador. Interfaces del proceso educativo confirman importantes contribuciones para una formación sólida, proyectan el enfermero en el nivel teórico/ académico y establece un camino para la formación Stricto Sensu. E xpectativas, motivaciones y potencialidades for talecen las contribuciones para una gobernanza contextualizada del proceso educativo y las demandas de la contemporaneidad para la E nfermería del Trabajo.

Descriptores: E nfermería del trabajo. E ducación en enfermería. E ducación superior. Salud laboral. T ítulo: $L$ a búsqueda de formación especializada en enfer mería del trabajo por el enfermero.

\section{ABST RACT}

This article examines and discusses the search for specialized formation in 0 ccupational $\mathrm{H}$ ealth $\mathrm{N}$ ursing for nurses. T his is an exploratory descriptive qualitative study whose data w ere analyzed using content analysis. D ata collection took place in M ay, 2010 with nine students from a specialization course that agreed to participate. All participants signed a free and informed consent term. The search for specialized formation is gover ned by the perspective for professional practice in $\mathrm{O}$ ccupational $\mathrm{H}$ ealth $\mathrm{N}$ ursing and specificity of the cur ricul um in occupational heal th. Interfaces of the educational process confirm important contributions to a solid formation, projects nursing to theorical/ academic levels and sets a path for the Stricto Sensu formation. Expectations, motivations and potentialities contributes to a contextualized governance of the educational process and the contemporary demands for $\mathrm{O}$ ccupational $\mathrm{H}$ ealth $\mathrm{N}$ ursing.

D escriptors: 0 ccupational health nursing. E ducation, nursing. E ducation, higher. 0 ccupational health.

T itle: Search by specialized training in occupational health nursing by nurses.

\footnotetext{
a Extraído do trabal ho de conclusão do Curso de Especialização em Enfermagem do T rabal ho apresentado em 2010 na Escola de Enfermagem da U niversidade Federal do Rio Grande do Sul (UFRGS).

${ }^{\text {b}}$ Enfer meiro do T rabalho, M estrando do Programa de Pós-G raduação em Enfermagem da U FRG S, Porto Alegre, Rio G rande do Sul, Brasil.

c M estre em Educação, D outoranda do Programa de Pós-Graduação em Enfermagem da UFRGS, Professora Assistente da Escola de Enfermagem da UFRGS, Porto Alegre, Rio G rande do Sul, Brasil.
} 


\section{INT RODUÇÃO}

A Enfermagem do T rabal ho contemporânea se estrutura na Política Nacional de Segurança e Saúde do T rabalhador (PNSST) e visa garantir que o trabal ho, base da organização social e direito humano fundamental, seja realizado em condições que contribuam para uma melhor qualidade de vida e saúde ao trabalhador, visando uma realização pessoal e social, e a redução da morbi-mortalidade dos trabal hadores mediante a execução de ações integradas e articuladas de prevenção, promoção, reabilitação e vigilância na área de saúde do trabalhador ${ }^{(1)}$.

A tuar na promoção da saúde, portanto, al meja valorizar o ser humano em sua totalidade e contribuir na redução de acidentes e doenças do trabalho, na qual a formação de qualidade do enfermeiro do trabalho é o diferencial. Contudo, nem sempre foi assim.

N o século XVIII, com a Revolução I ndustrial, à medida que ocorreu o progresso técnico, decorreram condições de trabalho precárias, preocupando os profissionais de saúde com o aumento das taxas de morbidade e mortalidade, com acentuada redução da longevidade dos trabalhadores. Com o desenvolvimento industrial crescia o lucro, e concomitantemente, o número de acidentes, doenças e sofrimento operário(2).

A pós a primeira Guerra M undial o movimento operário adquiriu bases sólidas e atingiu grande força política. A principal reivindicação foi a redução da jornada de trabalho, que posteriormente deu lugar à luta pela melhoria das condições de trabalho, segurança, higiene e prevenção de doenças. A miséria operária, na luta pela sobrevivência, modifica seu foco em torno da luta pela saúde, favorecendo o surgimento da medicina do trabalho, da fisiologia do trabal ho e da ergonomia laboral(2).

A regulamentação da saúde do trabalhador, no Brasil, ocorreu a partir da década de 80, contexto de transição democrática, iniciando-se uma nova forma de pensar o processo saúde-doença e 0 papel do trabalho. Período caracterizado pela coexistência de epidemias, doenças profissionais clássicas e o surgimento de novas formas de adoecimento pelo trabalho advindo das mudanças nas práticas laborais frente à globalização, modernização da economia e reivindicações sindicais por melhores condições de trabalho. É poca que surge a formação especializada de profissionais em saúde do trabalhador e a estruturação dos cursos de especialização em E nfermagem do T rabal ho no Bra$\mathrm{sil}^{(3)}$.

Os Programas de Pós-G raduação Stricto Sensu tiveram papel relevante na formação de enfermeiros docentes por titularem mestres e doutores, incitando linhas de pesquisa voltadas à saúde do trabalhador. Cientificidade e demanda em saúde do trabalhador aliam-se, contribuindo na estruturação da Enfermagem do T rabal ho como produtora de conhecimento e formadora de profissionais capacitados para a práxis ${ }^{(3)}$.

Conforme o Plano N acional de E ducação, os cursos de especial ização $\mathrm{L}$ ato $S$ ensu tratam da educação formal que gera uma certificação/ habilitação profissional específica, geralmente voltada à inserção no mercado de trabalho sob a identificação dos programas de educação profissional, educação superior e educação pós-graduanda(4).

Promover a especialização em Enfermagem do Trabalho é, então, mais que deparar o enfermeiro a conteúdos de saúde pública, é abarcar questões do dia a dia laboral que permeiam a sua atuação e determinam os conhecimentos teóricos e práticos em saúde do trabal hador, os aspectos legais envolvidos na busca da promoção da saúde e a prevenção de acidentes e doenças ocupacionais.

Este artigo decorre de inquietudes geradas a partir do trabal ho de conclusão de curso de E nfermagem do T rabal ho L ato Sensu da E scola de Enfermagem da U niversidade Federal do Rio G rande do Sul (UFRGS)(5).

0 processo educativo e de formação constitui-se como um imperativo para o enfermeiro que busca a excelência em sua aprendizagem, uma prerrogativa que aprofunda e complementa, inclusive, habilidades e atitudes no enfer meiro do trabal ho(6).

Direcionar a formação profissional implica no enfrentamento de novos desafios, requer uma abordagem pedagógica que intervenha em contextos de incertezas e complexidades que construam sensibilidade e responsabilidade profissional de forma integral a inserir os profissionais como sujeitos sociais, utilizando o processo dialético açãoreflexão-ação vinculado ao cenário da prática, almejando a sua transformação(7).

Formar enfermeiros do trabalho tem, então, como desafio, combinar as inúmeras diferenças entre a vivência na prática dos discentes, contextualizando-as teoricamente, dando sentido ao saber, promovendo a compreensão do mundo no 
intuito de buscar a transcendência aos limites do processo educativo ${ }^{(8)}$. U ma questão provocadora e leva em conta demandas do mercado de trabaIho para uma formação profissional especializada de qualidade.

0 ensinar deve ser neutro e ético. Criar situações que provoque um pensar crítico e debates no grupo de discentes visa construir e não impor o conhecimento. Para isto, o professor é essencial $(9,10)$.

Já o processo formativo enseja, nesta mesma ótica, uma participação ativa do enfermeiro em formação na construção do seu conhecimento. Ao expor suas opiniões, a apropriação do conhecimento adapta-se à realidade aproximando processos históricos e contemporâneos, perspectiva que promove uma atuação crítica que transforma realidades ${ }^{(10,11)}$.

M etodologias ativas, como processo educativo, val orizam a problematização da realidade e permitem ao discente a construção de competências articuladas aos processos de trabalho institucionais de forma ampla e integral(12).

0 compromisso de articular a formação e 0 exercício profissional às reais e atuais tendências da E nfermagem do T rabalho incita a formação de um profissional promissor, eficiente e eficaz, é ensejo de um processo formativo em curso e uma responsabilidade do professor.

É prudente em um curso de Enfermagem do T rabal ho se contemplar uma governança de gestão atualizada, cuja organização curricular conceba propostas atuais e que vá além delas, aborde a ação docente e discente voltada para as soluções necessárias, como um pensar rapidamente, resolver novas situações, adaptar-se, combinar, substituir, avaliar decisões e mudar de posição, quando necessário. T rabalhar os condicionantes atuais da E nfermagem do T rabal ho em estreita relação com projetos que abrem horizontes, integrando cada vez mais o todo da sociedade em busca de sentido e gênese da prática social, do próprio saber, ensinar e apreender é um diferencial(13). D esta forma, estar-se-á formando enfermeiros do trabalho intelectuais, cidadãos e qualificados para atuar em diferentes níveis de complexidade da assistência ao trabalhador em sua integralidade, no contexto das organizações, conjunturado ao Sistema Ú nico de Saúde (SUS) e ao sistema de saúde complementar em uma perspectiva crítico-reflexiva-criativa e compromissado com a qualidade de vida de familiares e comunidade. Formação que almeja uma qualificação permanente de desenvolvimento do trabal hador e do enfermeiro do trabalho.

Seguindo esta direção, foi objetivo do estudo conhecer o significado da busca pela formação especializada em Enfermagem do T rabalho, solicitando-se resposta a questão norteadora: 0 que rege a busca da formação especializada em E nfer magem do T rabal ho por enfermeiros?

A relevância do artigo está no problematizar e discutir interfaces do processo educativo valoradas na procura da especial ização $L$ ato Sensu por discentes enfermeiros, contribuindo com informações e conhecimentos relevantes acerca do processo educativo e de formação especializada que definem essa busca, agregando contribuições para uma gover nança contextualizada em Enfermagem do T rabalho.

\section{METODOLOGIA}

Estudo exploratório descritivo com abordagem qualitativa de dados realizada por meio da técnica de análise de conteúdo o(14), consider ando a busca por uma formação especializada em E nfermagem do T rabal ho por enfermeiros, com motivos, crenças, atitudes e valores que permeiam esse univer so das relações.

0 estudo foi realizado na E scola de E nfermagem da UFRGS, com al unos do curso de especialização em E nfermagem do T rabal ho, edição 20082010. Os dados foram coletados em maio de 2010.

0 convite de participação foi feito aos 23 discentes matriculados no curso de especialização da E scola de Enfermagem da U FRGS. Foi critério de inclusão concordar e estar inter essado em participar do estudo. Fizeram parte do estudo os nove primeiros discentes do curso que confirmaram 0 aceite em participar da pesquisa, todos enfermeiros, considerando a saturação dos dados. Q uando se percebeu que já não havia nada de novo a acrescentar no que se referia ao objeto estudado encerrou-se a coleta. Os participantes em idades entre 22 e 35 anos, sendo um do sexo masculino. Graduaram-se em diferentes $E$ scolas de E nfermagem do Estado do Rio Grande do Sul e atuam em distintas áreas de trabal ho da enfermagem. D entre eles, três já atuam na área da E nfermagem do T rabalho.

A coleta das informações foi realizada por meio de entrevista semi-estruturada. Seu roteiro solicitava respostas a questionamentos sobre informações pessoais, motivos que levaram os dis- 
centes a se inscrever no curso de E nfermagem do T rabal ho e de procurar por esse desenvolvimento, permitindo, assim, a inferência de conhecimentos relativos à busca da for mação especializada para além dos significados imediatos.

0 horário das entrevistas foi agendado com os participantes de acordo com sua disponibilidade, sendo realizada em uma sala de aula da Escola de Enfermagem, garantindo a privacidade e inexistência de interrupções. As entrevistas foram gravadas em mp3, e após, transcritas. Tanto gravações como transcrições ser ão guardadas por cinco anos pelos pesquisadores e posteriormente destruídas.

A análise dos dados deu-se em três momentos. Primeiramente organizaram-se as idéias iniciais das respostas dos discentes ao questionamento feito. A pós, passou-se para a exploração dos dados, quando se chegou a duas unidades de significação: motivos que levaram à procura do curso e busca por conhecimento e interfaces do processo educativo.

Por fim, uma riqueza de categorias evidenciou-se naturalmente das contribuições dos discentes sob o signo de suas contingências históricas na busca por formação especializada em Enfermagem do T rabalho, o que per mitiu a inferência de conhecimentos acerca das informações recebidas.

Respeitaram-se os direitos e deveres que dizem respeito à comunidade científica, aos participantes da pesquisa e ao E stado, atendendo à Resolução 196/ 96 do Consel ho Nacional de Saúde, que incorpora, sob a ótica do indivíduo e das coletividades, os quatro referenciais básicos da bioética: autonomia, não mal eficência, beneficência e justiça ${ }^{(15)}$.

0 projeto de pesquisa foi aprovado pela Comissão de Pesquisa da Escola de Enfermagem da U FRGS, sob o parecer $n=50 / 09$, e pelo Comitê de Ética em Pesquisa daquela U niversidade, processo $n^{\circ}$ 23078.039472/09-10, cadastrado no Sistema de Pesquisa da UFRGS sob o no 17447.

A concordância de participação no estudo foi registrada em Termo de Consentimento Livre e Esclarecido específico, sendo assinado em duas vias, permanecendo uma de posse do participante e outra dos pesquisadores. Foi informado o objetivo e metodologia da pesquisa, as finalidades da participação enquanto sujeito, as garantias de anonimato, da confidencialidade, da privacidade e do direito de declinar da participação enquanto discente a qualquer momento, se assim o desejasse, sem nenhum prejuízo.

Com o objetivo de manter 0 anonimato dos participantes do estudo, foi-Ihes solicitado se identificarem através das letras ESP (E specialista) seguido numericamente de 1 a 9 .

\section{RESULTADOS E DISCUSSÃO}

D uas importantes unidades de significação destacam-se no estudo: motivos que levaram à procura do curso e busca por conhecimento e interfaces do processo educativo; cujas informações trazidas pelos participantes foram contrastadas com a literatura existente na área, constituindo-se em um trabalho desafiador para compor a proposição de oferta de novos cursos de especialização.

A primeira unidade de significação, motivos que levaram à procura do curso, trata da trajetória dos participantes do estudo que antecedeu a escolha pelo curso de especialização, trazendo fortemente perspectivas para uma atuação profissional em E nfermagem do T rabalho.

D estacam-se diferentes trajetórias pessoais e únicas ao longo das vidas dos enfer meiros estudados.

H ouve quem justificou a busca do curso pela necessidade de titulação e aprimoramento, mesmo já atuando na área.

A necessidade me trouxe aqui, pois trabalho em uma empresa como enfermeira do trabal ho. T inha que obter a especialização e adquirir mais conhecimento para a minha prática (E SP 5).

Tal situação alia titulação profissional e experiência na prática, ensejo que requer regulamentação para uma atuação profissional.

A importância de construir o processo educacional articulado com a formação profissional e as necessidades sociais tem como perspectiva melhorar a atuação profissional, tendo em busca a participação consciente e crítica no mundo do trabal ho por parte do trabalhador, favorecendo efetivar a sua auto-realização profissional ao integrar habilidades teóricas e práticas ${ }^{(16)}$.

A especificidade dos conteúdos curriculares em saúde do trabalhador também foi motivo de busca para a formação especializada. 
Participei de al gumas palestras sobre saúde do trabaIhador do CEREST e gostei dos assuntos abordados. Quando fui buscar a minha especialização, mechamou a atenção que havia aber to as inscrições para o curso de E nfermagem do Trabalho aqui na instituição, eu ia poder justamenteaprofundar o que me cativou naquela palestra (E SP 3).

Os Centros de Referência em Saúde do T rabal hador (CEREST s) são locais que desempenham o papel de suporte técnico e científico de pólos irradiadores do trabalhador no processo de produção social e adoecimento. No Brasil estão sob a coordenação da Rede $\mathrm{N}$ acional de A tenção I ntegral à Saúde do T rabal hador (RE NAST ). Como estratégia, os CEREST s desempenham suporte técnico de educação permanente que favorece a implantação da saúde do trabal hador em todo o país, além disso, compõem a retaguarda da rede de serviços sentinela em saúde do trabal hador, realizando ações de vigilância em saúde, de vigilância epidemiológica e de promoção à saúde do trabalhador ${ }^{(1)}$.

A atuação nos CEREST s tem por base a Política N acional de E ducação Permanente, que busca formar e capacitar profissionais da saúde para atender às reais necessidades populacionais preconizadas pelo SU S. A educação permanente, como processo educativo, enseja espaços pedagógicos onde o pensar e o fazer no trabal ho é um diferencial: uma responsabilidade das instituições de saúde no desenvolvimento do cotidiano das capacidades e práticas dos trabal hadores ${ }^{(17)}$.

A experiência extracurricular vivida por Esp3 levou a descobrir, na educação permanente, a saúde do trabal hador. I nclusive, foi o motivo referido pela procura especializada nesta área, o que aponta que iniciativas dessa natureza devem ser estimuladas.

A segunda unidade de significação, busca por conhecimento e interfaces do processo educativo, insurge em questões relacionadas ao desejo de aprender e ensinar.

Ao finalizar o processo formativo, aprender continua sendo um desejo:

$M$ e sinto preparado para atuar como enfermeiro do trabalho, mas preciso continuar estudando (E SP 1).

0 processo de aprender deflagra uma curiosidade crescente, que pode tornar 0 aprendiz capaz de construir uma crítica a partir do pensar so- bre o fazer e desenvolver competências que possam modificar a sua realidade ${ }^{(9)}$.

Formar com conhecimento e desenvolver competências em E nfermagem do $T$ rabalho requer um processo educativo que constrói/ reconstrói 0 saber para novas formas de resolver do enfermeiro. A tualizar-se permanentemente e adquirir novas capacidades para uma prática profissional de qualidade e que responda aos desafios e as constantes mudanças da profissão acompanha esse processo $^{(18)}$.

A formação não pode limitar-se à sala de aula, deve articular cenários instigantes, leituras, pesquisas e experiências a questionamentos individuais decorrentes, agregando valor social e desenvolvimento de competências interativas. D eve deixar de ser 0 espaço apenas de transmissão de informações para propiciar produção e construção do conhecimento, no qual o discente atua como sujeito da aprendizagem. I sto demanda ir atrás de respostas para as incertezas, analisar problemas e ir à busca de soluções, um aprender a aprender que orienta a busca por conhecimento $0^{(7,10-12)}$.

Permitir ao discente agregar competências humano-interativas com valor social para participar ativa e criticamente do processo de construção do conhecimento através de um ambiente estimulador caracteriza um processo formativo a partir de metodologias centradas na integração do saber acadêmico com a prática, formando profissionais críticos, reflexivos, abertos e flexíveis para novas formas de resolver ${ }^{(19)}$.

0 papel do docente contribui nesse despertar do aprender a aprender pelo discente. M otivar o seu auto-desenvolvimento agrega valores e práticas ao processo educativo que enseja um saber especial izado em E nfermagem do T rabal ho, cal cado em estudos e experiências profissionais contemporâneos e com lastro para uma aprendizagem contextualizada.

Dedicar uma particular atenção aos atores sociais envolvidos no processo de formação: docentes; discentes; enfermeiros do trabalho; demais trabalhadores dos cenários da prática; comunidade, suas trajetórias e acumulações, isso favoreceria a troca de experiências, valores e capacidades para melhor enfrentar o mundo do trabalho. Associar teoria acadêmica e prática profissional é um diferencial que agrega expectativas e motivações às potencialidades de transformação, por trabalhar os condicionantes atuais da profissão( ${ }^{(18,20)}$. 
Esse importante fator motivacional para 0 aprendizado é dito:

Seria importante trazer enfermeiros do trabalho atuantes no mercado para falar de seu dia a dia nos encontros presenciais. E studar seria um diferencial para mim e o grupo. A profundar estas especificidades da saúde do trabalhador é uma necessidade que procuramos suprir. Seria um suporte para nossas inquie tações (E SP 7).

Ensinar e aprender, necessariamente, estão presentes e se entrelaçam no desenvolvimento do pensamento, ciência e contexto da profissão na formação de profissionais. Ao docente compete estimular 0 aluno por meio de conteúdos e práticas atualizadas, superando-se para vencer a dicotomia entre pensar e fazer, fortemente associada às práticas contemporâneas. Ao discente, em contrapartida, incumbe à responsabilidade por sua formação, a busca por auto-desenvolvimento e ampliação de sua visão para além dos muros da universidade $^{(20)}$. Responsabilidades e comprometimentos para um processo educativo e de for mação bem sucedidos $^{(7,18)}$.

T orna-se, então, evidente o quão importante é o processo educativo e de formação do enfermeiro do trabalho. É no ensino especializado onde ocorre sua projeção para o mercado de trabalho.

A prender e ensinar confirma importantes contribuições que incutem na especial ização $L$ ato Sensu expectativas para uma formação sólida e que integra o itinerário formativo tão bem lembrado:

E stou com uma grande expectativa em relação ao meu trabalho de conclusão de curso. Como terminei a graduação há bastante tempo, não tenho trabalhos publicados. A gora, certamente, irei transformá-lo em meu primeiro artigo. 0 curso que estou fazendo fará com queeu tenha uma produção científica [ ...] poderei concorrer na próxima seleção do mestrado, aprofundando inqui etações como enfermeiro do trabal ho (E sp2).

D etal he esse que promoveu não apenas a busca pela especialização, um diferencial que projeta o discente para além da formação profissional de enfermeiro do trabalho. Permite-lhe colocar-se em outro patamar teórico/ acadêmico, o qual atribui ao processo educativo e de for mação especializada $L$ ato Sensu: uma etapa para a formação Stricto Sensu contextualizada.

\section{CONSIDERAÇÕES FINAIS}

Formação especializada é uma opção de oferta de curso que requer dedicação, tenacidade e visão profissional voltada para mudanças e oportunidades nas instituições de ensino superior. A lém de potencializar as qualidades individuais, um curso de especialização em Enfermagem do T rabalho precisa instigar o discente de modo a desenvolver o amadurecimento necessário para um despertar profissional responsável, ético e, acima de tudo, preocupado com a saúde e as condições de trabaIho. Para isso, docentes e discentes devem interatuar nas instituições formadoras em prol da produção e construção do conhecimento.

E specializar-se em E nfermagem do T rabalho vislumbra um processo educativo e de formação que relacione conhecimento acadêmico e prática profissional de qualidade como resposta aos desafios e às constantes mudanças da profissão e do mercado de trabal ho.

A pesar da prática profissional do enfermeiro do trabalho ser variável, visto que é possível atuar em diversos tipos de empresas, indústrias e serviços, e ainda em diferentes níveis de atenção, a base de conhecimento construída por cada profissional enseja prepará-lo a desenvolver atividades de promoção e educação em saúde, vigilância em saúde do trabal hador e consulta de enfer magem. A ções intrínsecas do enfermeiro do trabalho que dignificam tanto sua imagem quanto uma atuação plena.

A expressão das expectativas dos discentes em relação ao potencial de transformação em suas vidas enquanto futuros enfermeiros do trabalho, tão recheada de subjetividades, revelaram trajetórias desde a busca por ingresso no curso até a conclusão do mesmo, trazendo importantes contribuições para o seu aprimoramento. Formação que não pode acontecer de qualquer maneira, nem tampouco limitar-se aos aspectos práticos do fazer docente, devendo conglomerar dimensões relativas às questões éticas, afetivas e político-sociais que permeiam o processo educativo da Enfermagem do T rabalho para enfrentar a expansão e as demandas da contemporaneidade, contributo da busca especializada em Pós- G raduação $L$ ato $S$ ensu.

Trazer à tona as interfaces do aprender e ensinar Enfermagem do T rabalho, sob a ótica da procura por formação especializada agregou expectativas, motivações e potencialidades como contri- 
buições para uma gover nança contextualizada do processo educativo. Indica que em uma experiência formativa exitosa, a satisfação do discente influencia no seu retor no em situações futuras e na própria recomendação da formação profissional, que isto decorre da avaliação da qualidade do curso pela estreita relação entre saberes e escol has.

\section{REFERÊ NCIAS}

1 M inistério da Saúde (BR), Coordenação T écnica de Saúde dos Trabalhadores. M anual de gestão e gerenciamento da rede nacional de atenção integral à saúde do trabalhador - RENAST [ I nternet] . São PauIo; 2006 [ citado 2009 nov 11] . D isponível em: http:/ / portal.saude.gov.br/portal/ arquivos/pdf/ M anual Renast07.pdf.

2 Dejours C. A loucura do trabalho: estudo de psicopatologia do trabal ho. 5a ed. São Paulo: Cortez; 1992.

3 D uran ECM , Robazzi M LCC, M arziale M H P. Conhecimento de enfermagem em saúde do trabalhador oriundo de dissertações e teses. Rev $\mathrm{G}$ aúcha Enferm. 2007;28(3):416-23.

4 M inistério da E ducação (BR), Instituto $\mathrm{N}$ acional de Ensino e Pesquisa. Plano nacional de educação [ Internet]. Brasília (DF); 2001 [ citado 2009 nov 11]. Disponível em: http:// www.inep.gov.br/ download/ cibec/ 2001/ titulos_avulsos/miolo_PNE.pdf.

5 Paz PO. O piniões de discentes sobre sua formação em um cur so de especial ização em enfermagem do trabalho [ monografia] . Porto A legre: Escola de Enfermagem, U niver sidade Federal do R io G rande do Sul; 2010.

6 U niversidade Federal do Rio Grande do Sul, Escola de Enfermagem, Programa de Pós-G raduação $L$ atoSensu. Regimento dos cursos de P ós- $G$ raduação $L$ atoSensu da E scola de E nfermagem. Porto A leg re; 2006.

7 M itre SM , Batista RS, M endonça J M G, Pinto N M M , $M$ eirelles $C A B$, Porto $C P$, et al. M etodologias ativas de ensino-aprendizagem na for mação profissional em saúde: debates atuais. Ciênc Saúde Colet. 2008;13(Supl 2):2133-44.

8 Angnes DI, Reinhardt RD, Gomes KC, M enezes AG, David CT N, Borba SB, et al. M apeamento das instituições formadoras de recursos humanos na saúde: nível de graduação do estado do Rio G rande do Sul.
In: Angnes DI, Bellini M IB, organizadores. Perfil profissional ea for mação em saúde no Rio G rande do Sul. Porto A legre: Escola de Saúde Pública, Secretaria de Estado da Saúde do Rio G rande do Sul; 2006. p. 2785.

9 F reire P. Pedagogia da autonomia: saberes necessários à prática educativa. 38a ed. São Paulo: Paz e T erra; 2008.

10 Kaiser DE, Serbim AK. Diretrizes curriculares nacionais: percepções de acadêmicos sobre a sua formação em enfermagem. Rev G aúcha Enferm. 2009; 30(4):633-40.

11 Freire P. E ducação e mudança. $31^{\text {å }}$ ed. Rio de Janeiro: Paz e T erra; 2008.

12 Semim GM , Souza M CBM , Corrêa AK. Professor como facilitador do processo ensino-aprendizagem: visão do estudante de enfermagem. Rev Gaúcha Enferm. 2009;30(3):484-91.

13 Bagnato M HS, Renovato RD, Bassinello GAH. De interdisciplinaridade e multireferencialidade na educação superior em saúde. Cogitare E nferm. 2007;12 (3):365-70.

14 M inayo M CS. Pesquisa social: teoria, método e criatividade. 13a ed. Petrópolis: Vozes; 1994.

15 M inistério da Saúde (BR), Conselho N acional de Saúde, Comitê N acional de Ética em Pesquisa em Seres H umanos. Resolução 196, de 10 de outubro de 1996: diretrizes e normas regulamentadoras de pesquisa envolvendo seres humanos. Brasília (D F); 1996.

16 A mâncio Filho A. Dilemas e desafios da formação profissional em saúde. I nterface Comun Saúde E duc. 2004;8(15):375-80.

17 M inistério da Saúde (BR), Secretaria de G estão do T rabalho e da E ducação na Saúde, D epartamento de G estão da E ducação em Saúde. Política nacional de educação permanente em saúde [ I nternet] . Brasília (DF); 2009 [ citado 2010 maio 11] . Disponível em: http:/ / portal saude.gov.br/ portal/ arquivos/ pdf/ volume9.pdf.

18 Simões AJC. M otivações e expectativas profissionais dos estudantes de enfermagem: estudo numa escola da área de Lisboa [ dissertação] . Lisboa: U niversidade A berta; 2008. 
19 Backes DS, Erdmann AL. Formação do enfer meiro pelo olhar do empreendedorismo social. Rev G aúcha Enferm. 2009;30(2):242-8.
20 Vega EJIF, Llovez JJ M. M aestría en salud de los trabajadores en Cuba: pasado, presente y futuro. Rev Cub Salud T rabajo. 2004;5(1):53-7.
Endereço da autora / Dirección del autor / Author's address:

D agmar E laine Kaiser

Rua São M anoel, 963

90620-110, Porto Alegre, RS

E-mail:dagmar@enf.ufrgs.br
Recebido em: 08/ 06/ 2010

A provado em: 15/ 01/ 2011 